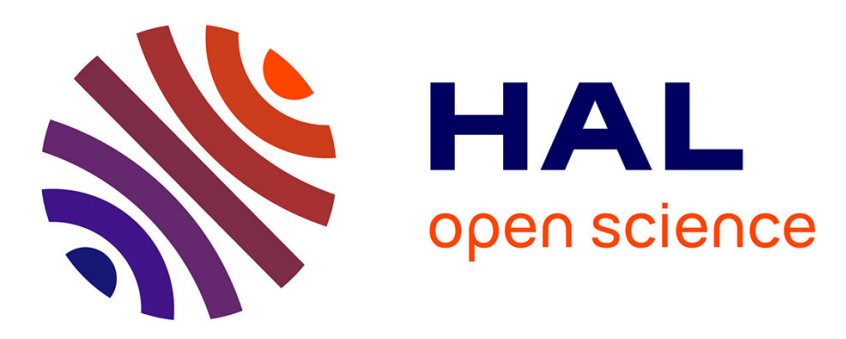

\title{
Plasma-Enhanced Chemical Vapour Deposition of Amorphous Se Films
}

P. Nagels, E. Sleeckx, R. Callaerts

\section{To cite this version:}

P. Nagels, E. Sleeckx, R. Callaerts. Plasma-Enhanced Chemical Vapour Deposition of Amorphous Se Films. Journal de Physique IV Proceedings, 1995, 05 (C5), pp.C5-1109-C5-1115. 10.1051/jphyscol:19955131 . jpa-00253828

\section{HAL Id: jpa-00253828 https://hal.science/jpa-00253828}

Submitted on 1 Jan 1995

HAL is a multi-disciplinary open access archive for the deposit and dissemination of scientific research documents, whether they are published or not. The documents may come from teaching and research institutions in France or abroad, or from public or private research centers.
L'archive ouverte pluridisciplinaire HAL, est destinée au dépôt et à la diffusion de documents scientifiques de niveau recherche, publiés ou non, émanant des établissements d'enseignement et de recherche français ou étrangers, des laboratoires publics ou privés. 


\title{
Plasma-Enhanced Chemical Vapour Deposition of Amorphous Se Films
}

\author{
P. Nagels, E. Sleeckx and R. Callaerts \\ RUCA, University of Antwerp, 2020 Antwerpen, Belgium
}

\begin{abstract}
The preparation of layers of amorphous Se by plasma-enhanced CVD using the hydride $\mathrm{H}_{2} \mathrm{Se}$ as precursor gas is described. Using a mixture of $15 \mathrm{vol} \% \mathrm{H}_{2} \mathrm{Se}$ in $\mathrm{H}_{2}$, partly crystallized films were obtained. Information concerning the structure of the films was obtained from Raman spectroscopy. The spectra of amorphous Se indicated that the dominant molecular structure is the eight-membered ring and/or a chain with $\mathrm{Se}_{8}$ molecular fragments. The optical transmission spectrum was recorded at different temperatures in the range $77-300 \mathrm{~K}$. The optical bandgap $\mathrm{E}_{\mathrm{T}}$ was calculated from the optical absorption coefficients $\alpha$ using Tauc law : $\alpha$ hv $=\mathrm{C}\left(\mathrm{hv}-\mathrm{E}_{\mathrm{T}}\right)^{2}$, where hu is the photon energy. The temperature dependence of $\mathrm{E}_{\mathrm{T}}$ can be approximated by a linear relation : $\Delta \mathrm{E}_{\mathrm{T}}\left(\mathrm{T}_{2}-\mathrm{T}_{1}\right)=-7.6 \times 10^{-4} \times\left(\mathrm{T}_{2}-\mathrm{T}_{1}\right)$.
\end{abstract}

\section{INTRODUCTION}

Because of its commercial importance, amorphous Se has been investigated extensively and is one of the most understood amorphous semiconductors. One advantage of Se over other amorphous materials such as $\mathrm{Si}$ and $\mathrm{Ge}$ is that it can be prepared either in bulk form by quenching from the liquid state or as thin films. Most studies on amorphous Se have dealt with thin films prepared by evaporation. A complicating feature is that Se crystallizes in two different structures. The stable form is trigonal, in which the atoms are arranged in spiral chains. A metastable monoclinic form exists which is built up by finite molecules in the form of $\mathrm{Se}_{8}$ rings. Since the short-range order of corresponding crystalline and amorphous materials is generally the same, the question arises whether the two types of short-range order, i.e. chains and rings, are present in amorphous Se.

Amorphous Se has played an important role in the understanding of the electrical and optical properties of amorphous semiconductors. The concept of the formation of "charged dangling bonds" was originally applied to the case of Se. It is generally accepted that isolated coordination defects can occur in the noncrystalline state. Any chain end of amorphous Se will be the site of a dangling bond. This isolated defect contains one electron and is electrically neutral. Mott et al. [1] postulated that neutral dangling bonds are transformed into positively and negatively charged dangling bonds. According to this view an electron is transferred from one neutral dangling bond $\left(\mathrm{D}^{\circ}\right)$ to another which becomes negatively charged (D), containing two spin-paired electrons. The other Se site which has an empty orbital forms a bond with the lone pair of a neighbouring atom. The defect now becomes threefold coordinated and positively charged $\left(D^{+}\right)$. The idea of spin-paired electrons at dangling bond sites has later on been extended to other amorphous semiconductor systems as well. The model has been compared in detail with a variety of experimental data.

An important observation in amorphous chalcogenide semiconductors containing sulphur, selenium or 
tellurium is the shift of the optical absorption edge to lower energies ("red " shift) or higher energies ("blue" shift). This photo-induced change has primarily been studied in thin films of arsenic chalcogenides $\left(\mathrm{As}_{2} \mathrm{~S}_{3}, \mathrm{As}_{2} \mathrm{Se}_{3}\right)$ and germanium chalcogenides $\left(\mathrm{GeS}_{2}, \mathrm{GeSe}_{2}\right)$. The films used in these investigations were prepared by vacuum evaporation. Little is known about this phenomenon in amorphous Se. Observation of photo-darkening i.e. a shift of the optical gap to lower energies has previously been reported [2-4] when Se films were illuminated at low temperature $(77 \mathrm{~K})$. It is interesting to examine the origin of photo-darkening in this elemental chalcogenide material, since it is built up only with homo-bonds.

In our study we have prepared films of amorphous Se by plasma-enhanced chemical vapour deposition (PECVD). This technique, although widely applied for the production of amorphous silicon, has rarely been used for the deposition of amorphous chalcogenides. We believe that PECVD is a promising technique for growing thin layers of these materials. Some of our previous work devoted to the depositon of amorphous $\mathrm{As}_{\mathrm{x}} \mathrm{S}_{1-x}, \mathrm{Ge}_{\mathrm{x}} \mathrm{S}_{1-\mathrm{x}}$ and $\mathrm{Ge}_{\mathrm{x}} \mathrm{Se}_{1-\mathrm{x}}$ was published recently [5-7].

\section{MATERIAL PREPARATION}

We have deposited thin films of amorphous Se $(1 \mu \mathrm{m}$ thick) in a plasma discharge stainless steel reactor. The experimental set-up, consisting of the reactor, deposition control systems and pumps, has been described in a previous paper [6]. A low pressure plasma of the order of 0.1 mbar was created by an $\mathrm{rf}$ discharge $(13.56 \mathrm{Mhz})$ between two parallel plate electrodes, $8 \mathrm{~cm}$ in diameter. In all experiments the separation between the powered (top) and grounded electrode (bottom) was kept constant at $3 \mathrm{~cm}$. The gas flows were controlled by electronic mass flow controllers. The gas pressure was measured and automatically regulated through a butterfly valve by a Baratron pressure gauge. Crystalline silicon and glass substrates were fixed on both electrodes. Depositions were made without additional heating of the substrate by a furnace, but due to heating by the plasma the temperature may rise to about $50^{\circ} \mathrm{C}$.

The precursor gases were pure $\mathrm{H}_{2} \mathrm{Se}$ or a mixture of $15 \mathrm{vol} \% \mathrm{H}_{2} \mathrm{Se}$ in hydrogen. The amorphous state of the films was checked by X-ray diffraction. Starting from pure $\mathrm{H}_{2} \mathrm{Se}$ completely amorphous material was obtained. However, when the hydride was diluted by hydrogen, the films were partly crystallized. Film growth ccurred only on the grounded electrode. The deposition conditions and resulting form of the material are given in Table 1.

Table 1

Precursor gas(es), deposition conditions and form of Se.

\begin{tabular}{||l|c|c|c|c||}
\hline \multicolumn{1}{|c|}{ Gas } & $\begin{array}{c}\text { Flow rate } \\
(\mathrm{sccm})\end{array}$ & $\begin{array}{c}\text { Pressure } \\
\text { (mbar) }\end{array}$ & $\begin{array}{c}\text { rf power } \\
\text { (Watt) }\end{array}$ & Form \\
\hline pure $\mathrm{H}_{2} \mathrm{Se}$ & 6 & 0.1 & 30 & amorph. \\
& 6 & 0.1 & 120 & amorph. \\
\hline 15 vol.\% $\mathrm{H}_{2} \mathrm{Se}$ & 40 & 0.1 & 30 & cryst. + amorph. \\
$+\mathrm{H}_{2}$ & 40 & 0.1 & 120 & cryst. + amorph. \\
\hline
\end{tabular}

The formation of crystalline material in a hydrogen-rich plasma can probably be explained by a selective etching of the amorphous material. This implies that the etching rate for the ordered material is lower than for the amorphous material, so that the proportion of ordered material will increase during deposition. A similar explanation has been given for the deposition of micro-crystalline silicon by plasma CVD in a highly reactive hydrogen plasma. 


\section{STRUCTURAL CHARACTERIZATION}

From the knowledge that the short-range order in crystalline and amorphous materials is generally the same, it is reasonable to assume that the two existing crystalline allotropes of Se can be present in amorphous Se. The stable form of crystalline Se is trigonal. Its lattice consists of spiral-like chains parallel to the c-axis (see Fig.1a). The helices contain three atoms per turn and are in an hexagonal array (close packing for rods). The interchain bonding is covalent, while the intrachain bonding is due to weaker Van der Waals attractions. Two similar metastable monoclinic forms of crystalline Se exist, $\alpha-$ monoclinic Se and $\beta$-monoclinic Se. The structural unit in both structures is a finite molecule in the form of a $\mathrm{Se}_{8}$ ring (see Fig. $1 \mathrm{~b}$ ). The difference between the $\alpha$ and $\beta$-monoclinic allotropes is a different stacking pattern within the respective unit cells. Thus monoclinic Se is molecular, whereas trigonal $\mathrm{Se}$ is polymeric. In all three crystalline forms, selenium is twofold coordinated and the covalent bond length is essentially the same $(2.32 \AA)$.
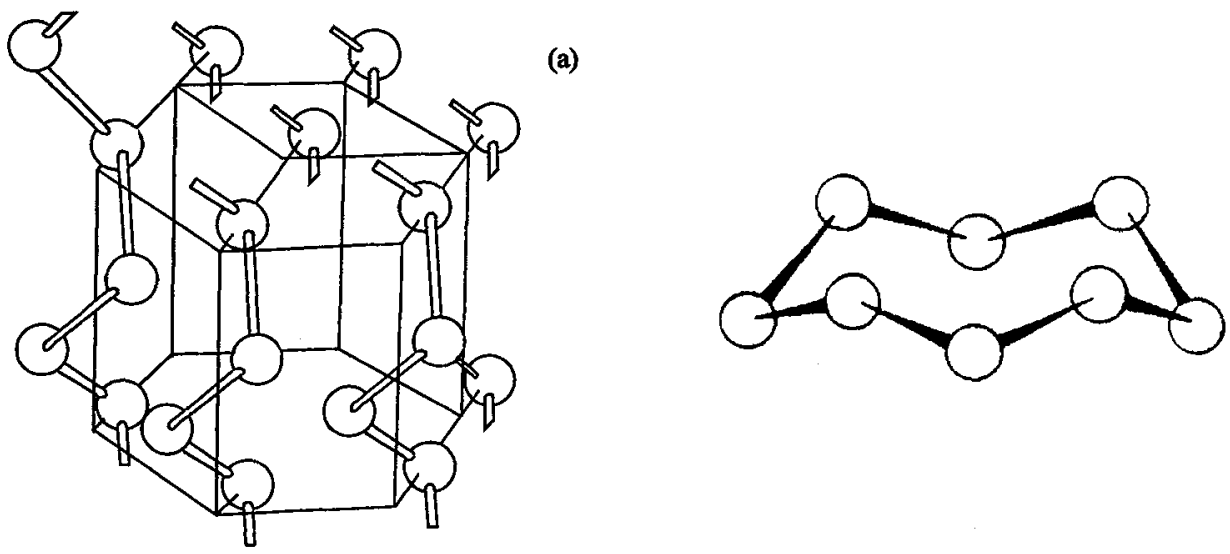

Figure 1 : Crystal structure of two allotropes of selenium; (a) trigonal; (b) structural unit $\left(\mathrm{S}_{\mathbf{8}}\right.$ ring) in monoclinic Se.

In the past the structure of amorphous Se has been studied by several authors using different techniques. By ordinary analysis of the X-ray radial distribution functions it is difficult to differentiate rings from chains and these results have been interpreted in very different manners. A clearer picture of the structure of amorphous Se emerges from Raman spectroscopy. These experiments gave evidence that the amorphous state can consist of the two allotropic forms which are mixed together : one is the $\mathrm{Se}_{8}$ ring and the other form is the helical chain.

We studied the structure of the amorphous Se film by Raman spectroscopy. Measurements were made with the help of a Bruker $66 \mathrm{~V}$ spectrometer in a reflection mode using a $1.06 \mu \mathrm{m}$ YAG : $\mathrm{Nd}^{+3}$ laser source. The Raman spectrum of an as-deposited Se film is shown in Fig. 2(a). It shows a strong peak at $250 \mathrm{~cm}^{-1}$ and two small bands at 80 and $112 \mathrm{~cm}^{-1}$. Moreover, a small shoulder appears at $235 \mathrm{~cm}^{-1}$ on the $250 \mathrm{~cm}^{-1}$ band. We also recorded the Raman spectra of an amorphous Se film prepared by vacuum evaporation and of a bulk glass quenched from $250^{\circ} \mathrm{C}$. Both spectra were similar to that of the plasma CVD film.

The Raman peaks of amorphous Se have been identified by Lucovsky et al. [8]. They observed a much closer resemblance of the Raman spectrum of melt quenched selenium to that of $\mathrm{Se}_{8}$ in monoclinic Se than to that of trigonal Se. In this paper they assigned the dominant peak at $250 \mathrm{~cm}^{-1}$ and the smaller bands at 80 and $112 \mathrm{~cm}^{-1}$ to vibrations in the $\mathrm{Se}_{8}$ ring. In trigonal Se the predominant Raman band lies at $235 \mathrm{~cm}^{-1}$. In a later paper Lucovsky [9] formulated some objections against a structural model which presumes a significant ring fraction in amorphous Se. He presented an alternative interpretation of the vibrational spectra that does not require discrete molecules. He proposed a structural model shown in Fig.3 

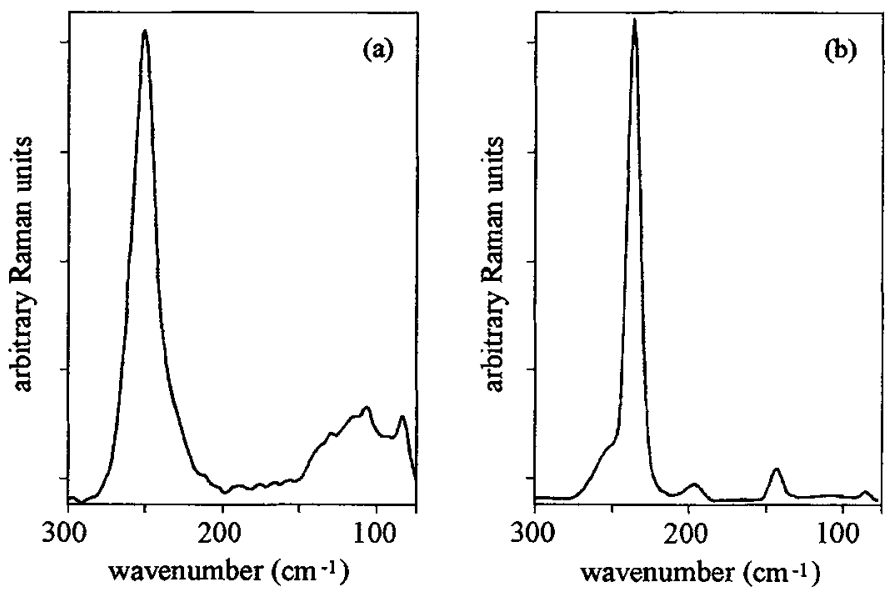

Figure 2 : Raman spectra of (a) as-deposited amorphous Se film; (b) annealed at $150^{\circ} \mathrm{C}$ for $1 \mathrm{hr}$.

and based on chains which include both helical chain-like and ring-like segments of the Se atoms (a "meandering" chain). Lucovsky assumed that a band at around $250 \mathrm{~cm}^{-1}$ can originate from bond stretching vibrations in $\mathrm{Se}_{8}$ fragments as well as in chain fragments. If we adopt these ideas then the Raman spectrum of our plasma CVD film indicates that the structure contains predominantly $\mathrm{Se}_{8}$ rings and $\mathrm{Se}_{8}$ molecular ring fragments containing 5 and $6 \mathrm{Se}$ atoms. The band at $250 \mathrm{~cm}^{-1}$ can be assigned to bond stretching vibrations and the band at $112 \mathrm{~cm}^{-1}$ to bond bending vibrations in the meandering chain. The shoulder that appears at $235 \mathrm{~cm}^{-1}$ band can be associated with a small fraction of "pure" helical chains. There is another piece of experimental evidence that speaks against a structural model which assumes a dominant fraction of $\mathrm{Se}_{8}$ rings in amorphous $\mathrm{Se}$. In the evaporated Se film we observed an identical Raman spectrum. In the past the composition of selenium vapour has been studied by a variety of experimental techniques. It is generally accepted that the vapour contains various types of species with predominance of $\mathrm{Se}_{5}, \mathrm{Se}_{2}, \mathrm{Se}_{6}$ and $\mathrm{Se}_{7}$ fragments. The $\mathrm{Se}_{8}$ ring is not a favoured species in the vapour phase and it seems unlikely that a rearrangement of the shorter molecular species to form eight-membered rings will occur on the substrate as the amorphous state is deposited.

Upon heating at $150^{\circ} \mathrm{C}$ for 1 hour the film was crystallized. The Raman spectrum (see Fig. $2 \mathrm{~b}$ ) showed a sharp peak at $235 \mathrm{~cm}^{-1}$ and a small shoulder at $250 \mathrm{~cm}^{-1}$. Upon crystallization the meander-like chains and the $\mathrm{Se}_{8}$ rings undergo transformation to the orderly array of chains of trigonal Se.

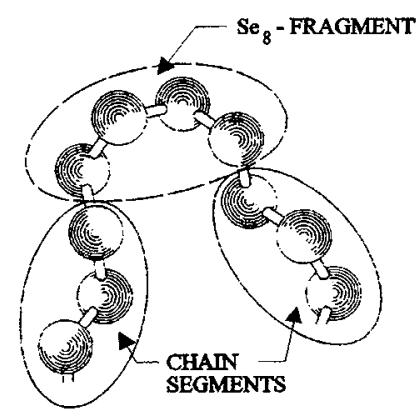

Figure 3 : Molecular order in amorphous Se : meandering chain with "chain-like" segments and "ring-like" segments ( $\mathrm{Se}_{8}$ fragments) (after Lucovsky G. [9]). 


\section{OPTICAL ABSORPTION}

Considerable work has been published on the optical absorption in amorphous semiconductors but its interpretation is not straightforward. In these materials the optical absorption spectrum is usually divided into two parts dealing with optical transitions at energies above and below the mobility gap, separating the extended from the localized states. Interband transitions between extended states in the valence and conduction band occur in the strong absorption region of the absorption edge. In this region the absorption coefficient $\alpha$ lies between $10^{3}$ and $10^{5} \mathrm{~cm}^{-1}$ (transmission range below $15 \%$ ).

Most of the experimental data on amorphous semiconductors in the strong absorption region were found to be in agreement with the so-called Tauc law, that is

$$
\alpha h v=C\left(h v-E_{T}\right)^{2}
$$

where hv is the photon energy.

The constant $E_{\mathrm{T}}$ can be used to define an optical gap. $C$ is a constant indicating how steeply the absorption rises with energy. A notable exception to the quadratic frequency dependence of $\alpha$ was found to be amorphous Se which followed a linear law [10]. The Se layer used in this experiment was a hotpressed sample obtained from a bulk glass.

We recorded the optical transmission spectrum at room temperature of an amorphous Se film prepared by PECVD (see Fig.4). Two features are immediately apparent :

1. the spectrum shows strong interference fringes and

2. the transmission drops markedly around $650 \mathrm{~nm}$.

The transmission range below $15 \%$ was used to determine the optical absorption coefficient $\alpha$ by inverting the equation

$$
T=\frac{(1-R)^{2} \exp (-\alpha d)}{1-R^{2} \exp (-\alpha d)}
$$

where $T$ is the transmission, $R$ the reflectance and $d$ the sample thickness.

We measured the reflectance $R$ as a function of wavelength and found a value of 0.27 .

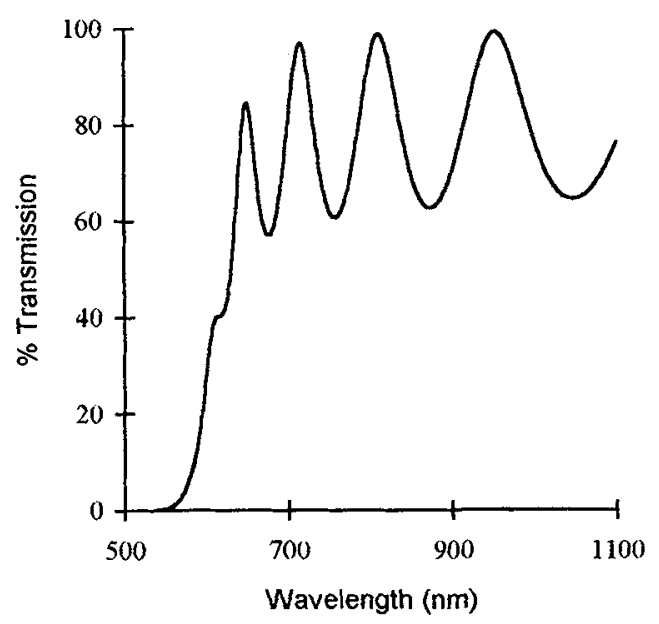

Figure 4 : Optical transmission spectrum of an as-deposited amorphous Se film recorded at room temperature. 
The experimental data of $\alpha$ were plotted versus photon energy in two ways : according to a linear law and according to Tauc law. A square root plot gave a better fit in the $2.1-2.4 \mathrm{eV}$ range. Figure 5 shows a Tauc plot in the form $(\alpha h v)^{1 / 2}$ versus hu for amorphous selenium. The transmission spectrum was recorded at room temperature. The extrapolated gap occurs at $\mathrm{E}_{\mathrm{T}}$ equal to $1.94 \mathrm{eV}$. Upon annealing to $100^{\circ} \mathrm{C}$, we did not observe any change in this spectrum.

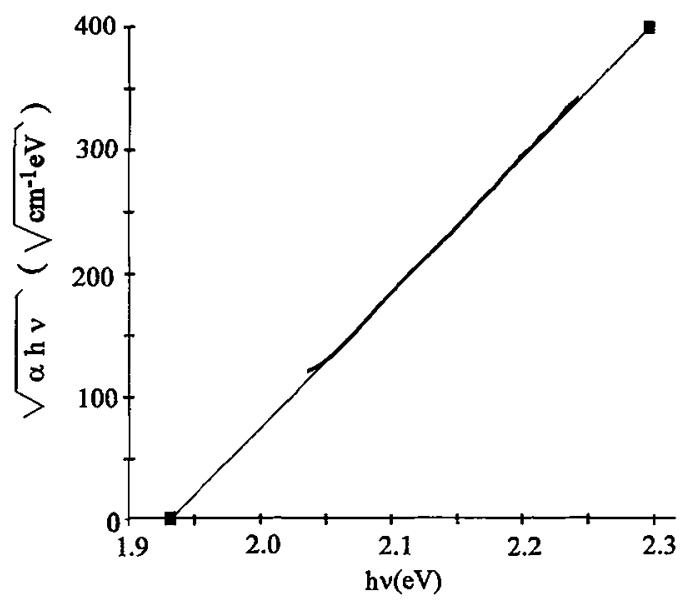

Figure 5 : Spectral dependence of the absorption coefficient $\alpha$ plotted in the form $(\alpha h u)^{1 / 2}$ against hu for an amorphous Se film (room temperature).

We measured the temperature dependence of the optical gap $\mathrm{E}_{\mathrm{T}}$ in the temperature range from $77 \mathrm{~K}$ to $300 \mathrm{~K}$ at temperature intervals of approximately $25 \mathrm{~K}$. The results are shown in Fig. 6, where $\mathrm{E}_{\mathrm{T}}$ is plotted versus the absolute temperature $T$. The values of $E_{T}$ were taken in all cases as the intercept of the $(\alpha h v)^{1 / 2}$ vs. hv curve for $\alpha=0$. The most frequently used relation for $\mathrm{E}_{\mathrm{T}}(\mathrm{T})$ has the simple form : $\mathrm{E}_{\mathrm{T}}(\mathrm{T})=\mathrm{E}_{\mathrm{T}}(0)-\alpha \mathrm{T}$.

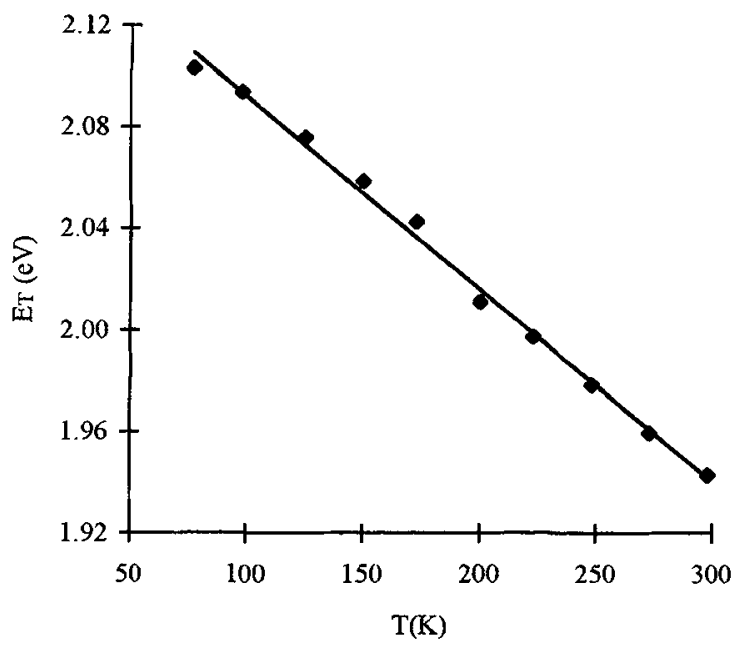

Figure 6 : Temperature dependence of the optical gap $\mathrm{E}_{\mathrm{T}}$ of amorphous Se. 
In our case the $\mathrm{E}_{\mathrm{T}}(\mathrm{T})$ dependence can also be approximated by a simple linear relation :

$$
\mathrm{E}_{\mathrm{T}}(\mathrm{T})=2.168-7.6 \times 10^{-4} \mathrm{~T}
$$

It means that in the temperature range from 77 to $300 \mathrm{~K}: \quad \Delta \mathrm{E}_{\mathrm{T}}\left(\mathrm{T}_{2}-\mathrm{T}_{1}\right)=-7.6 \times 10^{-4} \times\left(\mathrm{T}_{2}-\mathrm{T}_{1}\right)$.

We illuminated our Se films with white light from a halogen lamp (light intensity $100 \mathrm{~mW} \mathrm{~cm}^{-2}$ ) and recorded the transmission spectra before exposure and after illumination at $77 \mathrm{~K}$ for a period of 5 and 120 minutes, respectively. At room temperature no shift in the optical absorption edge was observed. The films illuminated at $77 \mathrm{~K}$ revealed a definite decrease in the optical bandgap-energy. This induced shift in the optical absorption edge could be completely removed when the samples were annealed at room temperature. The process was completely reversible. The saturated value of the shift $\Delta \mathrm{E}_{\mathrm{T}}$ was about $0.1 \mathrm{eV}$. Details about this investigation including a description of the origin of the phenomenon were published recently [11]. The observation of photo-darkening in this elemental material is an important feature, because it demonstrates that the occurrence of wrong homopolar bonds in heteropolar coordinated chalcogenide alloys is not a necessary condition.

\section{Acknowledgments}

We would like to acknowledge support in the Raman measurments from Prof. B. Van der Veken and Prof. H. Desseyn. This work was supported by the Belgium National Science Foundation (IIKW).

\section{References}

[1] Mott N.F.., Davis E.A. and Street R.A., Phil. Mog. 32 (1975) 961.

[2] Tanaka K. and Odajima A., Solid State Comm. 43 (1982) 961.

[3] Phillips RT., J. Non-Cryst. Solids 70 ( 1985) 359.

[4] Tanaka K, Jap. J. Appl. Phys. 25 (1986) 779.

[5] Nagels P., Callaerts R, Van Roy M and Vlcek M, J. Non-Cyyst. Solids $137 \& 138$ (1991) 1001.

[6] Sleeckx E., Nagels P., Callaerts R and Van Roy M., J. Phys. IV C3, 3 (1993) 419.

[7] Sleeckx, E., Nagels P., Callaerts R. and Van Roy M., J. Non-Cyst. Solids 164-166 (1993) 1195.

[8] Lucovsky G., Mooradian A., Taylor W., Wright G.B. and Keeze R. C., Solid State Comm. 5 (1967) 113.

[9] Lucovsky G., "Selenium, the Amorphous and Liquid State", in : The Physics of Selenium and Tellurium, E. Gerlach and P. Grosse Eds. (Springer Verlag, Berlin, 1979), p. 210 .

[10] Davis E.A., J. Non-Cryst. Solids 5, 107 (1970).

[11] Nagels P., Sleeckx E., Callaerts R and Tichý L., Solid State Comm. 94 (1995) 49. 